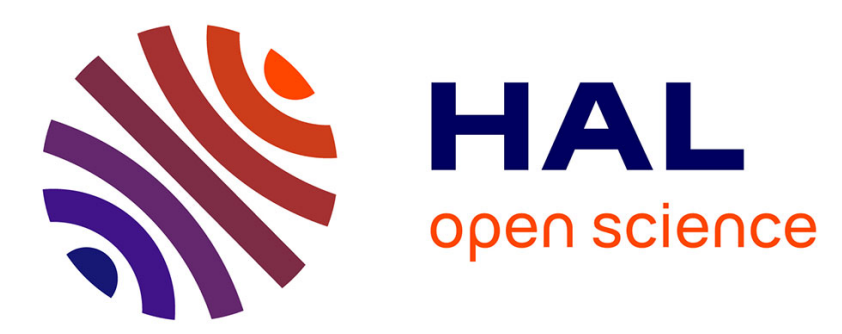

\title{
Physician satisfaction with transition from CPOE to paper-based prescription
}

Nicolas Griffon, M. Schuers, M. Joulakian, M. Bubenheim, J.-P. Leroy, S.J. Darmoni

\section{> To cite this version:}

Nicolas Griffon, M. Schuers, M. Joulakian, M. Bubenheim, J.-P. Leroy, et al.. Physician satisfaction with transition from CPOE to paper-based prescription. International Journal of Medical Informatics, 2017, 103, pp.42 - 48. 10.1016/j.ijmedinf.2017.04.007 . hal-01512739

\section{HAL Id: hal-01512739 \\ https://hal.sorbonne-universite.fr/hal-01512739}

Submitted on 24 Apr 2017

HAL is a multi-disciplinary open access archive for the deposit and dissemination of scientific research documents, whether they are published or not. The documents may come from teaching and research institutions in France or abroad, or from public or private research centers.
L'archive ouverte pluridisciplinaire HAL, est destinée au dépôt et à la diffusion de documents scientifiques de niveau recherche, publiés ou non, émanant des établissements d'enseignement et de recherche français ou étrangers, des laboratoires publics ou privés. 


\section{Physician satisfaction with transition}

\section{from CPOE to paper-based prescription}

Griffon $\mathrm{N}^{\mathrm{a}, \mathrm{b}, \mathrm{c}}$, Schuers $\mathrm{M}^{\mathrm{a}, \mathrm{d}}$, Joulakian $\mathrm{M}^{\mathrm{a}}$, Bubenheim $\mathrm{M}^{\mathrm{e}}$, Leroy J-P ${ }^{\mathrm{a}}$, Darmoni SJ ${ }^{\mathrm{a}, \mathrm{b}, \mathrm{c}}$.

a Department of Biomedical Informatics, Rouen University Hospital, F-76000 Rouen, France \& TIBS,

LITIS EA 4108, Normandie University, Rouen

b INSERM, U1142, LIMICS, 75006, Paris, France;

Sorbonne Universités, UPMC Univ Paris 06 UMR_S 1142, LIMICS, 75006, Paris, France;

Univ. Paris 13, Sorbonne Paris Cité, LIMICS (UMR_S 1142), 93430, Villetaneuse, France.

c Normandie Université, LITIS-TIBS EA 4108, Rouen Université, France

d Department of General Practice, Rouen University, France

e Department of Statistics, Rouen University Hospital, F-76000 Rouen, France.

Highlights

- Users reported poor satisfaction with the computerized provider order entry system.

- Reliability and user interface design are highly important in health information technology.

- The switch from computerized provider order entry towards paper based order entry was well accepted.

- Even in an emergency setting, the switch is possible with no perceptible impact on patient safety.

- Issues identified by a satisfaction survey eased the redeployment of computerized provider order entry. 


\section{Abstract}

Introduction: In January 2015, Rouen University Hospital's information system experienced serious issues. It was necessary to rapidly switch from the computerized provider order entry (CPOE) system towards a paper-based order entry (PBOE) system. This was an opportunity to evaluate prescriber opinion on the two provider order entry (POE) systems.

Methods: All residents were asked to fill an augmented version of the POE satisfaction and usage survey for both POE systems. The results were compared to identify the strengths and weaknesses of each system.

Results: Fifty-one respondents had used the CPOE system and the PBOE system. Overall, satisfaction was higher with PBOE than $\mathrm{CPOE}$ (odds ratio $(\mathrm{OR})=3.74 ; \mathrm{p}<0.001)$. Usability $(\mathrm{OR}=4.00 ; \mathrm{p}<0.001$ ), reliability $(\mathrm{OR}=8.54 ; \mathrm{p}<0.001)$, time consumption $(\mathrm{OR}=0.50 ; \mathrm{p}<0.05-$ survey statement was formulated negatively), and communication with nurses $(O R=14.27 ; p<0.0001)$ reached statistically better agreement. The more experience with CPOE the more residents were disillusioned with the reliability $(\mathrm{OR}=6.55 ; \mathrm{p}<0.01)$, the usability $(\mathrm{OR}=5.68 ; \mathrm{p}<0.01)$ and the patient safety $(\mathrm{OR}=0.27$; $\mathrm{p}<0.05$ - survey statement was formulated negatively) of CPOE. Although safety issues were reported for both systems, the causes were different; PBOE imposed frequent rewriting of the order while CPOE lack of usability might be unsafe. Another important issue with both POE systems was time consumption.

\section{Conclusion:}

Residents did not report any increase in safety issues with the rapid switch from CPOE to PBOE. They even seemed more satisfied with the rollback to paper, which remains a possible degraded mode in case of health information technology collapse.

\section{Keywords:}

Medical Order Entry Systems; cross-sectional studies; qualitative research; 


\section{Summary points}

\section{What was already known}

- Computerized provider order entry deployment has encountered difficulties in many countries.

- Feedback from users is useful to identify and manage problems when deploying a new application.

\section{What this study has added}

- It requires high commitment to take into account the numerous difficulties in computerized provider order entry deployment.

- It is possible to shut down parts of an information system.

- Paper based order entry as a degraded mode for prescription seems safe for patients.

\section{Introduction}

Computerized Provider Order Entry (CPOE) is largely described as a unique opportunity to enhance both the efficiency and the quality of care. In theory, CPOE allows a reduction in duplicate medications, drug overdoses, contraindications, unconsidered allergies, etc [1]. In practice, it reduces preventable adverse drug events [2]. While implementation of CPOE in hospitals in the USA [3][4] and in the Netherlands seems to be well underway, other countries lag far behind [5]. In the United Kingdom, vendors and adopters lack an understanding of how to design and implement generic solutions to meet diverse user needs [6]. In France, only $25 \%$ of university hospitals have achieved CPOE deployment [7], the other $75 \%$ are still struggling. In Germany, the rate of adoption of CPOE is very low $[8]$.

As a transformational technology [9], CPOE modifies the care process and has encountered some resistance during deployment. One important determinant of this resistance is user satisfaction [10][11]. Also, it is good policy to take into consideration feedback from user satisfaction surveys to allow better deployment of CPOE systems [12].

Rouen University Hospital (RUH) has been implementing CPOE (Horizon Expert Order, Maincare solutions) since June 2012. The CPOE system was deployed on a ward by ward basis for optimum fit with each ward's specialty prescription, and to train staff hospital-wide. However, in January 2015 after almost three years of partial deployment, it was necessary to shut down the CPOE system and the 
care plan for patient safety reasons. Indeed, some information loss had already been reported between the CPOE system and the care plan. Rather than taking any additional risks with patient safety, RUH decided to rollback to paper based order entry (PBOE).

The implementation of any information system is subject to failure and RUH is no exception. Nevertheless, failure often concerns just one function, or a few wards [13]. Despite calls for other hospitals to share experience on suboptimal implementation [14][15], only a few cases of failure have been described in the literature [16][17]. All of these reported failures, whether partial or total, have allowed the identification of factors associated with successful implementation of CPOE, which are now well described in the literature [18][19].

There have been difficulties with CPOE on RUH wards, mostly based on new processes, limited usability and increased prescription time which have been extensively documented in the literature [20]. Nevertheless, clinical leaders at our university hospital believed that the advantages of CPOE, as prescription quality, strongly outweighed the disadvantages. RUH staff learned to cope with the difficulties cited above. In reality, the shutdown was required because of insoluble technical factors (servers, network etc).

This exceptional situation allowed us to evaluate user satisfaction, both from paper based to computerized ordering and from computerized to paper based ordering.

The aim of this study was to identify changes in user satisfaction related to the switch from a CPOE system to a PBOE system. Residents' opinions on CPOE and PBOE were collected to evaluate the impact of such a rapid switch between POE systems and to better prepare the next attempt to implement a CPOE system. Potential influencing factors were also studied.

\section{Materials \& methods}

\section{Sequence of events at Rouen University Hospital}

RUH is a university hospital of 2,459 beds, employing a staff of more than 9,000 FTE (Full-Time Equivalent). The computerization of prescription at RUH began in June 2012. Wards were computerized one after the other. All physicians at RUH, residents and senior physicians included, had 
a 2-hour training session on the CPOE system. On January the $5^{\text {th }}, 2015$, at a time when about 1,500 beds were computerized, and approximately 180 residents used CPOE, we observed some information loss between the CPOE system and the care plan. Some drug prescriptions had not been transferred from the CPOE system to the electronic care plan, which clearly represented an unacceptable risk for patient safety. Three days later on January the $8^{\text {th }}$, as no solution had been reached, it was decided to shut down the CPOE system and rollback to PBOE, before any clinical morbidity occurred. The 3 day period between the bug report and the shutdown was used to (i) ensure that there was no existing solution and (ii) allow for an organized switch from CPOE to PBOE. This last item required all the physicians and nurses at RUH to transcribe orders from the CPOE system and the electronic care plan to their paper equivalent.

\section{Population studied}

Residents were the target population of this satisfaction study. In France, the first three years of medical school mainly involve acquisition of theory with little patient contact. The three following years consist in combined internship and study. After these six years of study, medical students choose a specialty and start their three to five-year residency program; although technically they are still considered as students, they enjoy increasing responsibility within the hospital as residents, under the responsibility of a senior physician. Residents represent the bulk of the medical workforce and use CPOE in their professional daily activity.

Residents were contacted by email through their Medical Students' Union, which was almost exhaustive, and, for wards with the most residents, by their senior physician. They were asked to complete the web-based questionnaire (see below). Three emails were sent on May the $21^{\text {st }}$, May the $28^{\text {th }}$ and June $3^{\text {rd }} 2015$. The web questionnaire was closed on June $15^{\text {th }} 2015$.

\section{Questionnaire}

Hoonakker et al. performed a literature review on the different available questionnaires to evaluate user satisfaction after CPOE deployment [11]. They chose the first part of the Physician Order Entry user Satisfaction and Usage Survey (POESUS) questionnaire [9]. This questionnaire was preferred 
because its internal consistency (Cronbach's $\alpha$ ) is high, it is dedicated to CPOE deployment and it has already been used for CPOE. For this exact same reason and also for comparability purposes, we decided to use the same questionnaire. The POESUS questionnaire consists in 16 statements scored on a 7-point Likert scale ranging from 1 = "never" to 7 = "always". This questionnaire was adapted to our situation; French translation, web transformation, and CPOE to PBOE transition. As both CPOE to PBOE and PBOE to CPOE transitions were studied, statements that were not comparative without a doubt were formulated twice: once for CPOE satisfaction and once for PBOE satisfaction (see table 1).

As CPOE deployment was recent, all residents included in the present survey had used the PBOE system. If residents had never used CPOE (never CPOE users) they filled questions that concerned only the paper-based prescription system without any comparison to another prescription system. If residents had already used CPOE (CPOE users) they filled questions that concerned only CPOE, only PBOE and questions that compared both prescription systems. In all cases, all residents were asked to state their gender, year of residency and CPOE experience. The last four statements (16 to 19) were added to the POESUS questionnaire ( 1 item was dropped) for more precise assessment of: communication between nurses and physicians, ease of access to prescription history, ease of writing complex orders and necessity to provide training to physicians when CPOE upgrades occur. The final list of statements is available in table 1 .

Depending on their use of $\mathrm{CPOE}$, residents were asked two to three open-ended questions. These questions allowed residents to specify: a list of adjectives qualifying each prescription system, the main differences between the two prescription systems and, the advantages and drawbacks of each solution.

This questionnaire was pre-tested by two general practice residents and one public health resident for face validity and to measure the time needed to fill it. 


\section{Qualitative analysis}

Free-text data were processed using open coding by NG and MS, without any pre-defined framework. Codes and emerging themes were compared for coding reliability through a process of discussion and deliberation. The analysis was completed entirely in French. Then, MS and NG translated the results, the categories, and the quotations into English. The accuracy of the translation has been validated by a native English speaker.

\section{Statistical analyses}

The study's principal aim was to identify changes in user satisfaction related to a switch from the CPOE system to the PBOE system, hence:

- For statements that were formulated only once, we ranked the observations to construct a $95 \% \mathrm{CI}$ for the median and claim there is a preference for one side of the scale if the indecision value, i.e. the middle point of the scale, is outside the confidence set

- For other statements, we assessed the homogeneity of the margins [21].

To identify factors that might influence the residents' answers, we used an ordinal regression model [21] to estimate the OR. The score test was used to seek whether there is evidence against the proportionality of the OR.

As this study was exploratory, a p-value below 0.05 was always considered as indicating a significant effect on the dependent factor.

For comparison with data in the literature, the average score and the Spearman correlation with the overall satisfaction (statement 15 of the POESUS questionnaire) were computed for each statement. 


\section{Results}

The questionnaire was filled by 71 residents. Twenty of them had never used the CPOE system. The characteristics of the population are reported in table 2 .

\section{Quantitative results}

\section{Satisfaction of CPOE users with the order entry system}

The results for statements formulated twice (once for PBOE and once for CPOE) are summarized in table 3. Significant differences were found for eight statements, all in favor of the PBOE system. Overall, users were almost four times more satisfied with paper than the electronic order entry system (statement 15). Exclusion of users with little CPOE experience- i.e. less than 3 months $-(n=10)$ led to similar results (data not shown).

The results of statements that were comparative by nature, or that exclusively concerned CPOE, are summarized in Figure 1. For all but two statements, the median score was equal to or very close to the indecision value. For statements 3 and 6 , the $95 \%$ confidence interval around the median did not include the indecision value. In both cases, users expressed a preference for the paper-based order entry system.

Figure 1 summarizes the distribution of answers given by residents for each statement. On the left (in blue) the answer is positive for PBOE, on the right (in green) the answer is positive for CPOE. For underlined statements (S3 and S6), median 95\% confidence interval excludes the indecision value (in white).

\section{Other determinants of satisfaction with the order entry system}

The results for major potential confounding variables are presented in Tables table 4 to 5. CPOE users expressed significantly higher agreement than never CPOE users for statement 1: PBOE is reliable $\left(\mathrm{OR}=3.84[1.47-10.06]_{95 \% \mathrm{CI}}\right) . \mathrm{CPOE}$ users expressed significantly lower agreement than never CPOE users for statement 14: $\mathrm{PBOE}$ is time-consuming $\left(\mathrm{OR}=0.38[0.15-0.97]_{95 \% \mathrm{CI}}\right)$. There were no significant differences for other statements (see table 4). 
For 10 statements among those formulated for paper and comparative by nature statements (S1, S2, S4, S5, S8, S9, S12, S13, S15, S16), higher year of residency was significantly associated with higher agreement with the statement - OR ranged from 1.5 to 2.5 (see Tables 4 and 5). In other words, a higher year of residency led to a higher level of satisfaction with the paper-based prescription system. Moreover, higher year of residency was associated with lower agreement with S3 (see table 5) and S14 (see table 4) - i.e. respondents with less experience thought that the PBOE system had a negative impact on patient care $\left(\mathrm{OR}=0.65[0.42-1.00]_{95 \% \mathrm{CI}}\right)$ and was time consuming $(\mathrm{OR}=0.66[0.47-$ $\left.0.93]_{95 \% \mathrm{CI}}\right)$.

The analysis of factors of agreement with CPOE statements showed that: (i) users in a higher year of residency expressed significantly higher needs for complementary training sessions (S19-OR $=1.76$ [1.16-2.66 $]_{95 \% \mathrm{CI}}$, and, (ii) the more experience with CPOE the less residents were satisfied by the reliability $\left(\mathrm{S} 1-\mathrm{OR}=6.55[1.76-24.39]_{95 \% \mathrm{CI}}\right)$ and the usability $\left(\mathrm{S} 5-\mathrm{OR}=5.68[1.54-20.97]_{95 \% \mathrm{CI}}\right)$ of CPOE. Other comparisons were not significant.

There was no difference in satisfaction according to gender, for any statement or for any order entry system (data not shown).

\section{Mean scores and correlation between statements}

The mean score for each statement, regarding transition from $\mathrm{CPOE}$ to PBOE and from PBOE to CPOE, was computed and is summarized in the supplementary material. Mean overall satisfaction, as measured by S15, was 2.96 for PBOE to CPOE transition and 4.63 for CPOE to PBOE transition. Spearman correlation coefficients between each statement and statement 15 were also computed and are available in the supplementary material. 


\section{Qualitative results}

Whatever the prescription system used, ordering was considered as a time consuming task.

Views regarding CPOE system

According to respondents, "crashes [were] recurrent" with CPOE and its use was "dependent on the quality of the network and devices". Bugs, delays in transmission of information to the care plan, and loss of prescription were identified by many respondents. These issues caused stress and irritation among residents: "Several times, I have had to restrain myself from throwing the computer out of the window!" The most problematic tasks concerned complex and unusual prescriptions. Many respondents expressed concerns about the readability of CPOE prescription: "treatments are totally irrational and all mixed up together; with enteral and parenteral administration grouped together, and sorted in alphabetical order ... total nonsense". Respondents also pointed out the possible disruption of communication processes between nurses and physicians. This well known issue did not seem to have been sufficiently taken into account: "[CPOE] can cause communication problems with nursing staff". Communication concerns and even conflict between staff members when using CPOE were cited. Last, browsing history was not seen as easy.

Even if CPOE complexity required training: "[CPOE is] better than the paper-based system if the user is trained", it was described as a modern and reliable tool, which allowed better traceability than

\section{PBOE.}

Views regarding PBOE system

The PBOE system was seen as archaic and obsolete by many respondents: "We could also prescribe on stone tablets". It was not seen as an ecological solution. Unlike CPOE, PBOE did not provide any warning system about drug interactions or dosing errors: "[CPOE] alerts us to contraindications [...] ]and helps us to avoid some mistakes". The need to periodically retype prescriptions was seen as a potential source of errors.

Nevertheless, this recurrent retyping "allowed us to reconsider each line of prescription" and seemed to be an opportunity to reevaluate patient medication and to optimize the prescription. Moreover, PBOE was considered as an easy-to-use solution, especially among non-regular prescribers 
intervening on a ward from time to time, during on-call periods for example. Respondents considered that a paper prescription could be "altered and reviewed [...] at the bedside", and that it was not dependent on unreliable network or applications. The ability for physicians to actually see the prescription, the care plan and any other document was positive: "I can look at the biology results at the same time as the paper prescription, whereas with a computer I have to open and manage multiple windows at the same time". Some respondents mentioned the "never out of order" aspect of PBOE: it "may lead to errors [...] (but at least it works)".

\section{Discussion}

Rouen University Hospital residents were almost four times more often satisfied (S15) with PBOE than CPOE. Significant results in favor of PBOE were observed for reliability, ease of use, availability of assistance, time-consumption, communication with nurses and complex prescription ordering. CPOE was never perceived as superior to PBOE. Qualitative analysis of open-ended questions confirmed dissatisfaction with RUH's implementation of CPOE. Results demonstrate the importance of reliability and user interface design in health information technologies (HIT).

Analyses also revealed that residents who had never used CPOE compared to residents who had already used CPOE were more critical of the reliability and time needed for PBOE. Moreover, respondents with little CPOE experience compared to those with more experience were more positive about CPOE reliability, ease of use and ability to reduce errors in patient care. RUH users did not seem to have any negative assumptions of CPOE. However, increased use of CPOE led to disillusionment concerning its application.

Analyses also revealed frequent bugs, crashes or problems with computerization. Fast and appropriate solutions to such problems might be acceptable during a rollout phase. Nevertheless, these concerns may arise at any time during the life cycle of a CPOE system and can seriously impact daily work. It is obviously crucial to set up an information system that minimizes such issues.

A study published in 2007 reported overdependence on HIT [22]. Even if a disaster recovery plan is mandatory in French Hospitals, there are no regular HIT crash tests and there have been few reports in 
the literature. Hanuscak et al. [23] attempted to measure the duration of HIT downtime, its causes and repercussions on medication error. Although the absence of a control group made their results difficult to interpret, the authors found that there was too much downtime either scheduled or not, and that medication errors occurred during downtime. Hsu et al [24] reported a 3.5 hour crash in a 17 year old CPOE system in a Korean hospital. The authors found many errors in hand written prescriptions that a CPOE would have prevented. These errors included absence of information, necessity of reconfirmation, inaccuracy, misspelling and unavailable dosages.

Despite two years and a half of electronic prescription at RUH, residents did not express any particular concerns regarding patient safety due to the switch from CPOE to PBOE - as demonstrated by the answers to S3, S4 and S9. This absence of concern suggests that such a switch is possible with no significant impact on patient safety. The three day period between the initial alert on the $5^{\text {th }}$ of January and the system shutdown on the $8^{\text {th }}$ of January allowed us to anticipate any disorganization due to unscheduled downtime and may partly explain these reassuring results. Nevertheless, it is noteworthy that rollback to PBOE is always an option.

According to the literature, overall satisfaction (S15) with CPOE ranged from 3.85 among physicians and nurses [25] to 5.29 among ICU staff [26]. For physicians only, POESUS score ranged from 4.56 [12] to 5.26 [9]. RUH residents only scored 2.96 for statement S15 regarding CPOE deployment. Overall, comparison with the literature revealed that CPOE deployment at RUH was not satisfactory with far poorer agreement with many statements. Residents at RUH were globally satisfied with the switch from CPOE to PBOE; overall satisfaction (S15) reached 4.63, which was similar to the score reported in the literature, and, overall, agreements with statements were closer to those observed in the literature.

Aarts [8] suggested that cultural issues play an important role in CPOE satisfaction Most of the issues we identified have already been discussed in the literature [12][27][20]: poor usability, timeconsumption, workflow interruption, etc. As reported by the institute of medicine [28], these issues are a threat to patient safety and the results of this survey were sufficient to justify a start-over of CPOE implementation, even without any information loss between the CPOE system and the care plan. 
Our study is probably the first to describe resident satisfaction after a CPOE to PBOE transition, a kind of study that is definitely not allowable in a prospective way for ethical reasons. The double formulation of statement for the two POE systems allowed a paired analysis that limited confounding factors.

The emergency shutdown of our CPOE system may explain some limitations of this present study.

First, it is not possible to generalize our findings from a population of residents to all impacted populations. Due to the emergency nature of the situation, a lack of time forced us to focus on one sub-population. As residents are less used to paper based prescription systems and as they rotate wards every 6 months, we thought that they would be less prone to resistance to change and accordingly we focused on this specific population. Other hospital staff, in particular nurses and pharmacists, do not use the CPOE system in the same way as physicians. Indeed, nurses' views on CPOE implementation are different to those of physicians [11][12]. Conversely, pharmacists seem more satisfied with CPOE implementation [29] than physicians [30].

Second, the same lack of time did not allow us to perform a proper validation of our adaptation of the POESUS questionnaire. One statement (S14) was substantially rephrased during the adaptation process; the statement formulated by Hoonaker et al [11] was: 'Overall, order entry saves me time'.

Third, it was hard to quantify the number of residents that had used the CPOE system during the 30 months of its implementation at RUH. However, the targeted population of residents working on a CPOE deployed ward at the moment of the rollback, comprised approximately 180 residents. Therefore, the response rate of our study was approximately $28 \%$, which may have biased our results. In addition, residents were asked for their level of satisfaction regarding transition from CPOE to PBOE and from PBOE to CPOE in the same survey.

In spite of the above limitations, PBOE rollback at RUH may be considered as a success, as there was no obvious collateral damage despite the emergency situation. Hence, PBOE would seem to be a satisfactory backup solution in an emergency setting. New implementation of CPOE will benefit from all the concerns raised by this present survey.

Even if CPOE systems induce adverse events [31], the controversy about the overall helpful or harmful effect of CPOE [32] is now behind us [2][33] as CPOE implementation is now mandatory in 
France [34]. Stavri and Ash [13] suggested that success is often preceded by failure. Indeed, all the information collected and analyzed during this survey was useful for re-implementation of the CPOE system at RUH and helped to prevent HIT fallacies [35]. As a consequence, the budget of the information systems department has been substantially raised to allow for complete reorganization, better documentation and purchase of new servers. Also, the information systems hotline has been reorganized to allow for better understanding and implementation of users' needs. There are now not only more computers but also newer computers on RUH wards, sometimes with multiple screens, easing visualization of medical records. Discussion with the CPOE supplier has resulted in a slight improvement in the readability of CPOE prescription.

In conclusion, our study shows that the residents included in our survey were globally satisfied with the rapid transition from CPOE to paper-based prescription. Despite the emergency setting, this transition was even better perceived than the earlier computerization, probably because of shortcomings in CPOE deployment. Furthermore, no specific safety issues were reported. Nevertheless, the clinical impact of health information technology adverse events must be closely monitored and minimized.

\section{Authors' Contributions}

SJD and JPL formulated the idea of this work. MJ, MS, NG and JPL adapted the POESUS questionnaire. MJ et JPL diffused it toward residents. NG and MB performed statistical analyses. NG and MS performed qualitative analysis. NG wrote the draft of the manuscript. All authors have reviewed the manuscript, made corrections and agreed on the submitted version.

\section{Conflicts of Interest}

The authors have no conflict of interest to disclose.

\section{Acknowledgements}

The authors are indebted to Nikki Sabourin-Gibbs, Rouen University Hospital, for her help editing the manuscript. We are also grateful to all the respondents who participated in the study. 


\section{References}

[1] Kaushal R, Shojania KG, Bates DW. Effects of computerized physician order entry and clinical decision support systems on medication safety: a systematic review. Arch Intern Med. 2003 Jun 23;163(12):1409-16.

[2] Nuckols TK, Smith-Spangler C, Morton SC, Asch SM, Patel VM, Anderson LJ, Deichsel EL, Shekelle PG. The effectiveness of computerized order entry at reducing preventable adverse drug events and medication errors in hospital settings: a systematic review and meta-analysis. Syst Rev 2014;3:56.

[3] HIMMS Analytics. (2016) Electronic Medical Record Adoption Model. Accessed on January 24, 2017. http://www.himssanalytics.org/provider-solutions\#block-himss-general-himss-provsol-emram

[4] The Leapfrog Group. Preventing medication errors in hospitals. Accessed on January 24, 2017. http://www.leapfroggroup.org/sites/default/files/Files/Leapfrog-Castlight Medication Safety Report.pdf

[5] Aarts J, Koppel R. Implementation of computerized physician order entry in seven countries. Health Aff (Millwood) 2009;28:404-14.

[6] Mozaffar H, Williams R, Cresswell K, Morrison Z, Bates DW, Sheikh A. The evolution of the market for commercial computerized physician order entry and computerized decision support systems for prescribing. J Am Med Inform Assoc 2016;23:349-55.

[7] DGOS: Atlas 2016 des SIH. Accessed on January 24, 2017. http://social-sante.gouv.fr/systemede-sante-et-medico-social/e-sante/sih/article/atlas-des-systemes-d-information-hospitaliers

[8] Aarts J. A sociotechnical perspective of electronic prescribing. In Saf Medicat Use. Edited by Tully MP, Franklin BD. CRC Press 2015;101-8.

[9] Lee F, Teich JM, Spurr CD, Bates DW. Implementation of physician order entry: user satisfaction and self-reported usage patterns. J Am Med Inform Assoc 1996;3:42-55.

[10] Hammana I, Lepanto L. Défis entourant le déploiement des ordonnances électroniques pour les tests diagnostiques au CHUM. Montréal. 2013:37. 
[11] Hoonakker PLT, Carayon P, Walker JM. Measurement of CPOE end-user satisfaction among ICU physicians and nurses. Appl Clin Inform 2010;1:268-85.

[12] Hoonakker PLT, Carayon P, Brown RL, Cartmill RS, Wetterneck TB, Walker JM. Changes in end-user satisfaction with Computerized Provider Order Entry over time among nurses and providers in intensive care units. J Am Med Inform Assoc 2013;20:252-9.

[13] Stavri PZ, Ash JS. Does failure breed success: narrative analysis of stories about computerized provider order entry. Int J Med Inform 2003;72:9-15.

[14] Silverstein SM, Wania C, Chen Y. Access patterns to a website on healthcare IT failure. AMIA . Annu Symp proceedings AMIA Symp 2006:1095.

[15] Ash JS. How to avoid an e-headache. BMJ 2007;334:1373.

[16] Aarts J, Doorewaard H, Berg M. Understanding implementation: the case of a computerized physician order entry system in a large Dutch university medical center. J Am Med Inform Assoc 2004;11:207-16.

[17] Peute LW, Aarts J, Bakker PJM, Jaspers MWM. Anatomy of a failure: a sociotechnical evaluation of a laboratory physician order entry system implementation. Int J Med Inform 2010;79:e58-70.

[18] Ash JS, Fournier L, Stavri PZ, Dykstra R. Principles for a successful computerized physician order entry implementation. AMIA Annu Symp proceedings 2003:36-40.

[19] Kruse CS, Goetz K. Summary and frequency of barriers to adoption of CPOE in the U.S. J Med Syst 2015;39:15.

[20] Niazkhani Z, Pirnejad H, Berg M, Aarts J. The impact of computerized provider order entry systems on inpatient clinical workflow: a literature review. J Am Med Informatics Assoc $2009 ; 16: 539-49$

[21] Agresti A. Categorical Data Analysis. New York, NY: John Wiley \& Sons Inc 1996.

[22] Campbell EM, Sittig DF, Guappone KP, Dykstra RH, Ash JS. Overdependence on technology: an unintended adverse consequence of computerized provider order entry. AMIA Annu Symp proceedings 2007:94-8. 
[23] Hanuscak TL, Szeinbach SL, Seoane-Vazquez E, Reichert BJ, McCluskey CF. Evaluation of causes and frequency of medication errors during information technology downtime. Am $\mathbf{J}$ Health Syst Pharm 2009;66:1119-24.

[24] Hsu C-C, Chou C-L, Chen T-J, Ho C-C, Lee C-Y, Chou Y-C. Physicians Failed to Write Flawless Prescriptions When Computerized Physician Order Entry System Crashed. Clin Ther 2015;37:1076-80.e1.

[25] Tan YM, Flores JVPG, Tay ML. Usability of clinician order entry systems in Singapore: an assessment of end-user satisfaction. Stud Health Technol Inform 2010;160(Pt 2):1202-5.

[26] Wilson JP, Bulatao PT, Rascati KL. Satisfaction with a computerized practitioner order-entry system at two military health care facilities. Am J Health-System Pharmacists 2000;57:218895.

[27] Carpenter JD, Gorman PN. What's so special about medications: a pharmacist's observations from the POE study. AMIA Annu Symp proceedings 2001:95-9.

[28] Institute of Medicine (IOM). Health IT and patient safety: building safer systems for better care. Washington, DC: National Academies Press 2011.

[29] McMullen CK, Macey TA, Pope J, Gugerty B, Slot M, Lundeen P, Ash J, Carlson N. Effect of computerized prescriber order entry on pharmacy: experience of one health system. Am J Health Syst Pharm 2015;72:133-42.

[30] Abdel-Qader DH, Cantrill JA, Tully MP. Satisfaction predictors and attitudes towards electronic prescribing systems in three UK hospitals. Pharm World Sci 2010;32:581-93.

[31] Wetterneck TB, Walker JM, Blosky MA, Cartmill RS, Hoonakker P, Johnson MA, Norfolk E, Carayon P. Factors contributing to an increase in duplicate medication order errors after CPOE implementation. J Am Med Inform Assoc 2011;18:774-82.

[32] Berger RG, Kichak JP. Computerized physician order entry: helpful or harmful? J Am Med Inform Assoc 2004;11:100-3.

[33] Jones SS, Rudin RS, Perry T, Shekelle PG. Health information technology: an updated systematic review with a focus on meaningful use. Ann Intern Med 2014;160:48-54.

[34] Arrêté du 6 avril 2011 relatif au management de la qualité de la prise en charge médicamenteuse et aux médicaments dans les établissements de santé (NOR: ETSH1109848A)

[35] Karsh B-T, Weinger MB, Abbott PA, Wears RL. Health information technology: fallacies and sober realities. J Am Med Inform Assoc 2010;17:617-23. 
S2. The PBOE system improves my productivity.

$\mathrm{S} 4$. The PBOE system reduces patient care errors.

66. Compared to CPOE, the PBOE system slows me down.

S9. The PBOE system improves the quality of patient care.

S13. Overall, the PBOE system improves the safety of care I provide.

S10. System response time on order entry is slow.

S11. I feel that I can benefit from refresher classes on the order entry system.

S19. I feel that complementary training sessions will be necessary when implementing new $\mathrm{CPOE}$ functionality.

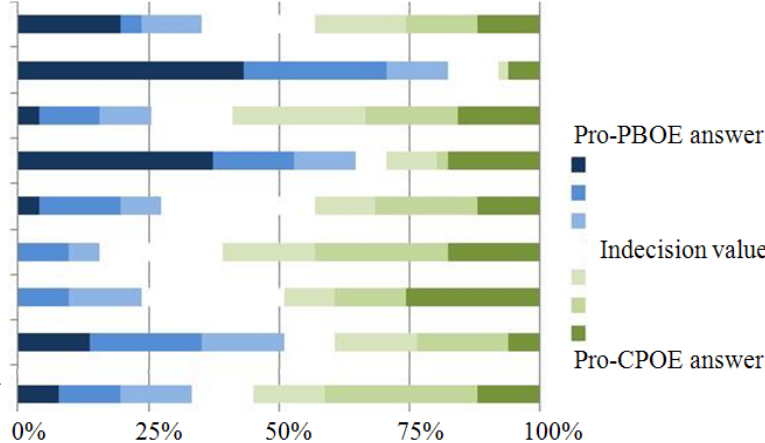

Figure 1: Responses for statements that were formulated only once (one mark in table 1) $(\mathrm{n}=51)$. 
Table 1: List of statements proposed to respondents.

S1. CPOE/PBOE is reliable.

$\mathrm{X} \quad \mathrm{X}$

S2. The PBOE system improves my productivity.

S3. The PBOE system has a negative impact on patient care.

$\mathrm{X}$

S4. The PBOE system reduces patient care errors.

$\mathrm{X}$

S5. CPOE/PBOE is easy to use.

X $\quad \mathrm{X}$

S6. Compared to CPOE, the PBOE system slows me down.

$\mathrm{X}$

S7. CPOE/PBOE gives me the information I need to write better orders. $\quad \mathrm{X} \quad \mathrm{X}$

S8. I feel that I had adequate training on CPOE/PBOE. $\quad X \quad X$

S9. The PBOE system improves the quality of patient care.

$\mathrm{X}$

S10. System response time on order entry is slow.

$\mathrm{X}$

S11. I feel that I can benefit from refresher classes on the order entry system.

S12. When I need help on CPOE/PBOE, I can find it.

X $\quad X$

S13. Overall, the PBOE system improves the safety of care I provide.

$\mathrm{X}$

S14. Overall, CPOE/PBOE is time-consuming.

X $\quad X$

S15. Overall, I am satisfied with CPOE/PBOE.

X $\quad X$

S16. Using CPOE/PBOE facilitates communication with nurses.

X $\quad X$

S17. It is easy to access prescription history with CPOE/PBOE.

X $\quad X$

S18. It is easy to write complex prescriptions with CPOE/PBOE.

X $\quad X$

S19. I feel that complementary training sessions will be necessary when implementing new CPOE functionality.

$\mathrm{X}$

Statements in the "Paper" column were formulated for PBOE and presented to all residents. Statements in the

"Computer" column were formulated for CPOE and presented only to residents that had used CPOE.

Statements in the "Both" column are comparative by nature and were presented to residents that had used CPOE.

Abbreviations: CPOE: Computerized Provider Order Entry; PBOE: Paper-Based Order Entry 
Table 2: Characteristics of respondents $(n=71)$
All respondents
only CPOE users
$\mathrm{n}=71$
$\mathrm{n}=51$

\begin{tabular}{lll}
\hline Gender $(\mathrm{n}-\%)$ & \\
Male & $27-38.0 \%$ & $17-33.3 \%$ \\
Female & $44-62.0 \%$ & $34-66.6 \%$ \\
Year of residency (median $-[\mathrm{Q} 1-\mathrm{Q} 3])$ & $2-[2-3]_{\mathrm{IQR}}$ & $3-[2-3.5]_{\mathrm{IQR}}$ \\
Age (median $-[\mathrm{Q} 1-\mathrm{Q} 3])$ & $27-[26-29]_{\mathrm{IQR}}$ & $27-[25.5-29]_{\mathrm{IQR}}$ \\
CPOE experience $(\mathrm{n}-\%)$ & \\
$<3$ months & & \\
$>3$ and $<12$ months & & $10-19.6 \%$ \\
$>12$ months & & \\
\end{tabular}


Table 3: Association between agreement with PBOE statements vs. CPOE statements for users of both systems $(\mathbf{n}=\mathbf{5 1})$

Statement $\quad \frac{\text { Median }}{\text { CPOE }} \frac{\mathrm{OR}^{*}}{\mathrm{PBOE}} \mathrm{p}^{\$}$

$\mathrm{S} 1 . \mathrm{CPOE} / \mathrm{PBOE}$ is reliable.

2

5

8.54

0.0002

S5. CPOE/PBOE is easy to use.

4

6

4.00

0.0002

S7. CPOE/PBOE gives me the information I need to write better orders.

$\begin{array}{llll}4 & 4 & 0.69 & 0.3187\end{array}$

S8. I feel that I had adequate training on CPOE/PBOE.

5

$4 \quad 0.79$

0.5352

S12. When I need help on CPOE/PBOE, I can find it. 3

$\begin{array}{lll}5 & 4.90 \quad 0.0003\end{array}$

S14. Overall, CPOE/PBOE is time-consuming. 4

5

0.50

0.0406

S15. Overall, I am satisfied with CPOE/PBOE.

2

5

3.74

0.0004

S16. Using CPOE/PBOE facilitates communication with nurses.

$\begin{array}{llll}2 & 5 & 14.27 & <0.0001\end{array}$

S17. It is easy to access prescription history with CPOE/PBOE.

$\begin{array}{llll}3 & 3 & 1.10 & 0.7769\end{array}$

S18. It is easy to write complex prescriptions with

$\begin{array}{llll}2 & 4 & 4.58 & 0.0001\end{array}$
CPOE/PBOE.

*: An OR >1 indicates that the odds of agreement with the statement is higher when using PBOE versus CPOE.

\$: test of marginal homogeneity

Abbreviations: CPOE: Computerized Provider Order Entry; PBOE: Paper-Based Order Entry 
Table 4: Factors of agreement with PBOE statements $(n=71)$

Statement

CPOE user

Year of Residency

(year)

\begin{tabular}{lll}
\hline S1. PBOE is reliable. & 3.84 & 1.71
\end{tabular}

S5. PBOE is easy to use. $\quad$. $\quad 1.93$

S7. PBOE gives me the information I need to write better orders.

S8. I feel that I had adequate training on PBOE.

S12. When I need help on PBOE, I can find it.

1.61

S14. Overall, PBOE is time-consuming. $\dagger$

0.38

0.66

S15. Overall, I am satisfied with PBOE.

1.65

S16. Using PBOE facilitates communication with nurses.

S17. It is easy to access prescription history with PBOE.

S18. It is easy to write complex prescriptions with PBOE.

Numerical values are OR statistically different from 1 (p<0.05). "." means there is no significant association. An OR > 1 indicates that the odds of agreement with the statement are higher in the reference group, i.e. the one in the column heading. As regards the influence of the year of residency, OR $>1$ indicates the amount by which the odds of agreement increase with every additional year.

$\dagger$ †igher agreement was positive for PBOE, except for statements S14.

CPOE users are 3.84 times more likely to agree that PBOE is reliable than never CPOE users.

Abbreviations: CPOE: Computerized Provider Order Entry; OR: Odds-Ratio; PBOE: Paper-Based Order Entry 
Table 5: Factors of agreement with comparative by nature statements $(n=51)$

$$
\text { CPOE }
$$

Statement

experience $<3$ Year of Residency

months (year)

S2. The PBOE system improves my productivity.

1.83

S3. The PBOE system has a negative impact on patient care. $\dagger$

S4. The PBOE system reduces patient care errors.

S6. Compared to CPOE, the PBOE system slows me down. $\dagger$

S9. The PBOE system improves the quality of patient care.

S13. Overall, the PBOE system improves the safety of care I provide.

Numerical values are OR statistically different from 1 ( $\mathrm{p}<0.05)$. “.” means there is no significant association. An OR $>1$ indicates that the odds of agreement with the statement are higher in the reference group, i.e. the one in the column heading. As regards the influence of the year of residency, OR $>1$ indicates the amount by which the odds of agreement increase with every additional year.

$\dagger$ Higher agreement was positive for PBOE, except S3 and S6.

Users in year 4 of residency are 1.83 times more likely to agree that PBOE improves productivity than users in year 3 of residency.

Abbreviations: CPOE: Computerized Provider Order Entry; OR: Odds-Ratio; PBOE: Paper-Based Order Entry 